\title{
Analysis of a Spanish energy scenario with Generation IV nuclear reactors
}

\author{
Raquel Ochoa Gonzalo Jimenez Sara Perez-Martin
}

\begin{abstract}
A B S T R A C T
The advantages of fast-spectrum reactors consist not only of an efficient use of fuel through the breeding of fissile material and the use of natural or depleted uranium, but also of the potential reduction of the amount of actinides such as americium and neptunium contained in the irradiated fuel. The first aspect means a guaranteed future nuclear fuel supply. The second fact is key for high-level radioactive waste management, because these elements are the main responsible for the radioactivity of the irradiated fuel in the long term.

The present study aims to analyze the hypothetical deployment of a Gen-IV Sodium Fast Reactor (SFR) fleet in Spain. A nuclear fleet of fast reactors would enable a fuel cycle strategy different than the open cycle, currently adopted by most of the countries with nuclear power. A transition from the current Gen-II to Gen-IV fleet is envisaged through an intermediate deployment of Gen-III reactors. Fuel reprocessing from the Gen-II and Gen-III Light Water Reactors (LWR) has been considered. In the so-called advanced fuel cycle, the reprocessed fuel used to produce energy will breed new fissile fuel and transmute minor actinides at the same time.

A reference case scenario has been postulated and further sensitivity studies have been performed to analyze the impact of the different parameters on the required reactor fleet. The potential capability of Spain to supply the required fleet for the reference scenario using national resources has been verified.

Finally, some consequences on irradiated final fuel inventory are assessed. Calculations are performed with the Monte Carlo transport-coupled depletion code SERPENT together with post-processing tools.
\end{abstract}

\section{Introduction}

The most famous definition of sustainability was included in the Brundtland report in 1987 [1]: "Sustainable development is development that meets the needs of the present without compromising the ability of future generations to meet their own needs". Another technical point of view about sustainability is the fact of no decreasing neither the environmental quality nor the individual one [2]. The human activities linked to sustainability are affected by three kinds of limitations: environmental, economic and social ones [3-5].

Many authors have classified the different energies in terms of sustainability [6] according to different parameters. They can be set into three: resources consumption, environmental impact and economical and technical availability. In case of nuclear energy, parameters such as no proliferation and nuclear safety should be also considered.
Regarding nuclear fission, the use of the current technology (Generation I to III+) has disadvantages in terms of resources availability for long term. An interesting option for Fuel Cycle is what is called "closed cycle" as it is the most sustainable option possible. Closed cycle means that the irradiated fuel, after being burnt and then cooled in the power plant spent fuel pool, is reprocessed as it still has around $0.6 \% \mathrm{Pu}-239$ and $0.7 \% \mathrm{U}-235$, which are the most common fissile materials. This $\mathrm{Pu}-239$ is used together with U-238 to make new fresh fuel, called MOX (Mixed Oxide) fuel, to be used again in power plants. Almost $94 \%$ of the irradiated fuel is U-238, which might be reused for fresh fuel too. The rest are fission products (FP) and minor actinides (MA), which are the most radioactive components of the spent fuel. Those materials (FP and MA) are normally vitrified to manage them in a much more stable solid form than their natural one. Those wastes have been considered to be stored in a geological deep repository, to avoid human and environmental contact for thousands of years.

In terms of efficiency, the total primary energy (the natural uranium at the mine) estimated to be transformed into heat in the fission process in a once-through cycle is $0.5 \%$. The $85 \%$ of the potential energy is still stored in the natural uranium unused in 
the process of fuel fabrication and the other $14.5 \%$ is stored in the spent fuel [7]. In terms of mass, in light water reactors with oncethrough cycles, only $3 \mathrm{~kg}$ of U-235 from each $1000 \mathrm{~kg}$ of natural uranium (99.3\% U-238 and $0.7 \% \mathrm{U}-235$ ) are used for generating heat. In a closed cycle with reprocessing, the used resource is doubled to $1 \%$. Therefore, there is a need of improvement in the fuel cycle as the major part of the resource is treated as a sub-product (depleted uranium) or as waste (spent fuel).

The most advanced fuel cycle strategy nowadays is not only based on spent fuel reprocessing to make new MOX fuel, but also on separation and transmutation of minor actinides and fuel breeding. The MA transmutation is meant to reduce the radioactive inventory of the spent fuel, while fuel breeding consists on generating fissile material (Pu-239) from non-fissile U-238. Actually fast reactors can produce more fuel than what they use in a cycle. The advanced fuel cycle strategy needs fast reactors as the sodium cooled one, which is the chosen system for the present analysis. The use of these reactors can wide the availability of resources for much more than 300 years, as they use very efficiently the fuel [8].

It is also important to underline the case of Thorium (Th-232) as a fuel for fast reactors. It can be transmuted into U-233, a fissile element that might be used in the actual thermal reactors. Thorium is a huge resource to be used, which is estimated to be 4.4 millions of tons among the known resources [9]. This resource can play an important role to make sure a long term development of nuclear energy, especially in countries like India [10].

Nuclear fission produces low $\mathrm{CO}_{2}$ emissions, even taking into account all fuel cycle process $\left(65 \mathrm{~g} \mathrm{CO}_{2} / \mathrm{kW} \mathrm{h}\right)$, compared with other energies like thermal plants $\left(600-1200 \mathrm{~g} \mathrm{CO}_{2} / \mathrm{kW} \mathrm{h}\right)$, solar panels $\left(90 \mathrm{~g} \mathrm{CO}_{2} / \mathrm{kWh}\right)$, and higher than wind or hydro power (30-65 $\mathrm{g} \mathrm{CO}_{2} / \mathrm{kW} \mathrm{h}$ ) [11-15].

In addition, a sustainable strategy for nuclear energy has to take into account the no proliferation and safety aspects [16,17]. In case of the no proliferation aspects, the fuel reprocessing process makes very difficult the Pu-239 isolation, as it is mixed with other isotopes such as Pu-240 and Pu-241. One advantage of a closed fuel cycle with MOX fuel is the possibility of recycling the military Pu for energy production. Regarding safety, sodium fast reactors have inherent safety characteristics due to the physical properties of the materials and the type of system (for example, pool type avoids coolant losses). There is a long experience of commercial operation with these reactors and some of them have operated for more than 35 years like Phenix, in France. However, they face some challenges in the next years for the massive implementation of this technology.

As a consequence of USA president Carter decision in 1977 [18], the United States stopped reprocessing in an attempt to limit the proliferation of nuclear weapons material. Since then spent fuel is stored intact in a repository, what is called once-through cycle.

Spain, as other countries like Canada, Finland or Sweden, followed later on that decision [19]. Before that moment Spain was reprocessing its spent fuel in other countries like France or UK. After that strategic change, the spent fuel pools of the Spanish nuclear plants slowly became full, as they were not designed to handle with the spent fuel of their operational life. Several actions were planned by the power plant owners such as re-racking the spent fuel pool or building an Individual Temporary Storage to store each plant's own wastes in shielded casks. All these expensive actions could have been avoided with a Centralized Temporary Storage (CTS). However the decision was delayed in the last years for political reasons till finally it was approved in December 2011. This storage will have enough room to cope with all the Spanish spent fuel and with the waste from reprocessing waiting in France to come back to Spain. Nevertheless, as its own name indicates, the CTS facility is a temporal solution for the high-level radioactivity wastes. Alternative technologies should be pursued to provide a definite solution to those wastes, and the reduction of the radioactive load of the wastes in fast reactors could be an interesting option to be investigated. Indeed, one feasible option is the mentioned advanced closed cycle, since the existing reprocessing plants have demonstrated the correct operability of the irradiated waste treatment and the occidental countries respect the non-proliferation treaties. These two aspects are the main reason to support the advanced fuel cycle in the study.

In this paper, a hypothetical Spanish energy scenario with sodium fast reactors is analyzed, testing if a fleet of nuclear fast reactors could solve any of the challenges that the nuclear industry is facing, such as nuclear waste management, security of supply and sustainability.

In the first part of the paper, the Generation IV reactors characteristics are briefly summarized, as they represent a step up to the nowadays Generation II and III/III+ reactors. Later on, the Spanish energy scenario is presented, introducing some sensitivity studies. Finally the detailed results and conclusions of the study are presented to show the influence in terms of energy production, resources availability and nuclear waste reduction.

\section{Reactor technology description - Sodium-cooled fast reactors}

The new nuclear power plant designs considered in Generation IV initiative pretend to overcome past and present design parameters in terms of sustainability, industrial competitiveness, safety and proliferation resistance. Additionally to power generation, these new designs will be used to generate industrial process heat and hydrogen production.

Sodium fast reactors meets these goals clearly and have many years of operational experience. Actually, they are in operation nowadays in countries like Japan, China or Russia and in a very short term India [20-22].

The two main advantages of SFR in terms of sustainability were explained in the introduction: the possibility of minor actinides transmutation and the capacity of breeding fuel. The main disadvantages are related with operational safety. Sodium could have a positive reactivity feedback in case of coolant voiding. This fact has a strong influence on the core design. Therefore many analyzes have been and are being done to get an optimal configuration design that avoids power excursions $[23,24]$. On the other hand, sodium is very reactive with water and air (oxygen), so the interfaces between those components must be reliable enough to avoid any contact in any case. Related with fuel fabrication, if transmutation of minor actinides is intended, difficulties in manufacturing (U,Pu, $\left.\mathrm{MA}^{1}\right)_{2}$ should be overcome, since fuel loaded with $\mathrm{MA}$ is highly radioactive.

\subsection{SFR core design}

The SFR core design used in this analysis corresponds to the new optimized core of the CP-ESFR European Project, from the European Community's Seventh Framework Program [24]. The basic core, called CONF2, with 3600 MWth contains oxide fuel in two concentrically regions, distributed in an inner and outer region. The outer region presents slightly higher plutonium enrichment in order to flatten the radial power shape at the end of the cycle. The active region of the core has a flattened shape of about $4.7 \mathrm{~m}$ in diameter by $1.0 \mathrm{~m}$ height. There exist five different types of sub-assemblies (SA), two fuel SA with a different isotopic enrichment, two control elements with different boron carbide compositions and one radial reflector assembly. Above the fuel SA there is a sodium plenum

\footnotetext{
${ }^{1}$ MA: Minor Actinides (Americium, Neptunium and Curium).
} 
and an absorber layer, covered by an axial shielding. Within the fuel SA below the active region there is a short fertile blanket zone followed by a long fission gas plenum. The fertile blanket contains depleted uranium oxide (UOX) pellets. Above the fissile pellets there is another fission gas plenum. The larger sodium plenum, absorber layer and fertile blanket have been added to the original configuration of the CP-ESFR as a result of an optimization effort to reduce the sodium void effect [23].

Some other configurations derived from the CONF2 have been used for different purposes along this work. CONF2-HET2 consists of the same configuration as CONF2, i.e. with the same isotopics in inner fuel, outer fuel and lower fertile blanket, but with an additional ring of SA's located in the place of the first reflector ring. That ring is filled with $20 \% \mathrm{MA}$ in the (U,Pu,MA) $\mathrm{O}_{2}$ matrix. This configuration is employed in Section 5.5.5 as a consequence of its better breeding properties. The CONF2-HOM4 configuration, on the other hand, consists in the same geometrical configuration as CONF2, but with $4 \%$ MA homogeneously loaded in the driven fuel and fertile blanket. It was used in Section 5.3 to analyze the transmutation performances.

A single batch approach for the whole irradiation period was assumed. In this approach, a cycle length of 2050 equivalent full power days (EFPD), divided into 5 cycles of 410 EFPD is considered, starting from fresh fuel, with no batch reloading. However, in reality a reload is envisaged each 410 EFPD. For this reason, the Pu production is estimated for each reloading cycle taking into account that $1 / 5$ of the assemblies of the core are substituted by fresh fuel assemblies after each 410 days.

\section{Methodology and codes}

In this section the computational methodology used to obtain the isotope inventories at the different stages of the SFR commercial operation is presented. For the cores described in the previous section, burn-up and decay calculations have been performed using the Monte Carlo transport-coupled depletion code SERPENT [25]. SERPENT is a three-dimensional continuous-energy Monte Carlo reactor physics burn-up calculation code developed at the VTT Technical Research Centre of Finland since 2004. The code is specialized in lattice physics calculations. Neutron transport is based on a combination of conventional surface-to-surface raytracing and the Woodcock delta-tracking method. SERPENT computes directly the effective delayed neutron parameters using a forward Monte Carlo method developed at NRG [26]. It is reported that compared to other coupled Monte Carlo calculation codes based on MCNP, the calculation time required by SERPENT to achieve a given statistical uncertainty has been reduced by a factor of 5-15. Burn-up depletion equations are solved by the advanced matrix exponential method CRAM $[27,28]$, providing a robust and accurate solution with a very short computation time.

As most of the Monte Carlo codes, SERPENT reads continuousenergy cross sections from ACE format data libraries. In this work, ACE format cross section libraries based on JEFF-3.1.1 evaluated data files are used. In addition, some pre- and post-processing tools were developed in order to treat the data and obtain the results.

\section{Spanish scenario hypotheses}

2011 Spanish electricity consumption was $252.848 \mathrm{GW} \mathrm{h}$, according to the Spanish nuclear industry forum [29]. Nevertheless the installed electrical power was $103.625 \mathrm{MW}$ (this would correspond to $907.755 \mathrm{GW}$ h working 365 days $24 \mathrm{~h}$, or $28 \%$ average utilization factor). With the current energy mix, nuclear electricity power represents $7.5 \%$ of the total installed power and $19.5 \%$ of the total production. This last value is much lower than in the nineties, when around $30 \%$ of the power plants were nuclear.

The historical electricity generation series is shown in Fig. 1 [29]. The average annual rate was about 5.5\% during the period 1995-2007. Last 4 years were affected by the economic contraction and therefore tendencies present a different slope and even a decrease during recession periods.

For the study of the future energy scenario in Spain we link the evolution of electricity consumption to national economic activity. We assume that electricity demand is a kind of macroeconomic variable with pro-cyclical behavior. This means that it increases during expansions and decreases during contractions. Regarding timing, it is not exactly a coincident variable, but just a slightly leading variable that reaches a peak or trough before the turning points of the business cycle. The period of study in this work is so extensive (2050-2110) that the trend of both variables, electricity demand and Gross Domestic Product (GDP) can be taken as coincident.

The relation between electricity consumption and economical activities is easy to understand in an industrial occidental economy, where mostly all economical businesses require electricity to work (industrial activities, public and private services, tourism, transport, leisure time, communication and information technologies). According to different international economical organisms such as the International Monetary Fund (IMF) and the European Central Bank (ECB) the growth rate for next decades will get back to stable positive values.

Since it is really complicated to predict the evolution of the national economy in a period of 50 years, we propose in this study three different scenarios. For the period 2011-2020 contraction and expansions seem to be the trend, so we consider neither increase nor decrease of GDP in this period. Therefore the electricity demand remains constant. For 2020-2050 time period a positive $1.5 \%$ annual growth rate is considered. And for the following 60 years (2050-2110), we propose three possible tendencies, shown in Fig. 2:

1. Moderate constant development $(+0.5 \%$ annual growth rate). This option is very moderate and represents the case where important energy saving policy as well as electricity distribution network improvement are applied.

2. High development by periods (combined cycles of $2.5 \%$ annual growth rate for 10 years plus zero growth for next 2 years and repeatedly). This option seems to be the most realistic one. According to economic cycle theories in different countries, in every decade there is a small contraction of the economy. Sometimes it can be deeper and sometimes lighter, but in average every decade undergoes a trend change.

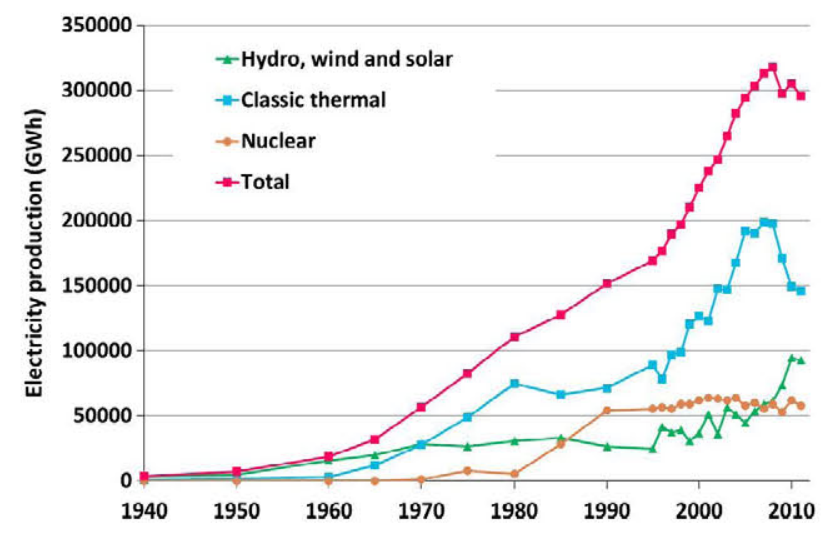

Fig. 1. Historical series of electricity production [29]. 


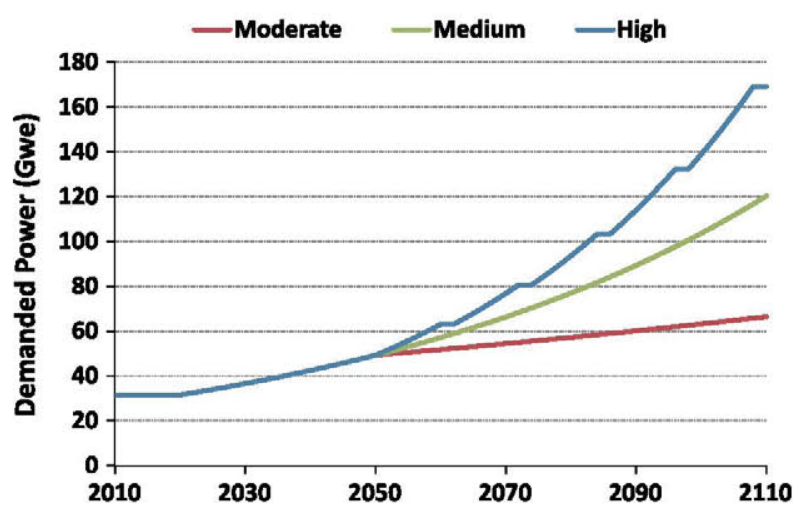

Fig. 2. Power demand evolution according to the postulated trends.

3. Medium constant development $(+1.5 \%$ annual growth rate). This option represents the case of a stable expansion economy and this will be the upper limit of most probable electricity demand.

\subsection{Spanish nuclear park and natural resources}

The characteristics of the Spanish nuclear fleet are shown in Table 1 [29]. Currently there are 7 nuclear reactors in commercial operation. They have a total power of $7753 \mathrm{MW}$, and in 2011 their contribution was $7.5 \%$ of the total power installed in Spain.

Initially the lifetime of the reactors was 40 years, but the license for operating is renewed every 10 years. According to last Spanish energy policy, further extension beyond 40 years are being studied for the future, following the procedures of other countries such as USA and Sweden where they extend the lifetime up to 60 years.

According to ENRESA PGRRS (General Radioactive Waste Plan) [19] data, the total nuclear waste accumulated from the Spanish nuclear power plants is calculated to be 6675 ton in 2030, if 40 years of operating life is assumed. Based on the possible lifetime extension, we consider that all current nuclear reactors will operate up to 60 years. That assumption is important, not only for the necessity of meeting the demand, but also for knowing the amount of irradiated fuel and specifically the plutonium content that could be reused in the future as fuel for fast spectrum reactors.

In addition to the lifetime extension and in order to give continuity in the nuclear park, an intermediate deployment of Gen-III fleet has been considered. According to this hypothesis, the current nuclear reactors would be substituted by their equivalent Gen-III technology right after the shut down of the previous generation, as explained in Table 2 .

Table 1

Spanish nuclear fleet characteristics and hypothetical operational lives.

\begin{tabular}{lcll}
\hline & $\begin{array}{l}\text { Electrical power } \\
\text { (MWe) }\end{array}$ & $\begin{array}{l}\text { Operational } \\
\text { starting }\end{array}$ & $\begin{array}{l}\text { Estimated end of } \\
\text { operation }\end{array}$ \\
\hline José Cabrera & 160 & 1968 & $2006^{\mathrm{a}}$ \\
Santa María de & 466 & 1970 & 2012 \\
$\quad$ Garoña & & & \\
Almaraz I & 980 & 1980 & 2020 \\
Almaraz II & 984 & 1983 & 2023 \\
Asco I & 1032 & 1982 & 2022 \\
Asco II & 1027 & 1985 & 2025 \\
Cofrentes & 1097 & 1984 & 2024 \\
Vandellos I & 480 & 1972 & $1989^{\mathrm{a}}$ \\
Vandellos II & 1087 & 1987 & 2027 \\
Trillo & 1066 & 1987 & 2027 \\
\hline
\end{tabular}

a Real end of operation.
Table 2

Equivalence between Gen-II and Gen-III fleet.

\begin{tabular}{lcllll}
\hline & Gen-II & & & Gen-Ill \\
\cline { 2 - 3 } \cline { 5 - 6 } & $\begin{array}{l}\text { Electrical power } \\
\text { (MWe) }\end{array}$ & Technology & $\begin{array}{l}\text { Electrical power } \\
\text { (MWe) }\end{array}$ & Technology \\
\hline Almaraz I & 980 & PWR-W & & 1154 & AP1000 \\
Almaraz II & 984 & PWR-W & & 1154 & AP1000 \\
Asco I & 1032 & PWR-W & & 1154 & AP1000 \\
Asco II & 1027 & PWR-W & & 1154 & AP1000 \\
Cofrentes & 1097 & BWR & & 1400 & ABWR \\
Vandellos & 1087 & PWR-W & & 1154 & AP1000 \\
$\quad$ II & & PWR-KWU & 1650 & EPR \\
Trillo & 1066 & & & &
\end{tabular}

In Spain there are uranium mines, closed for exploitation nowadays due to high economical costs compared to uranium price in international markets, but still natural resources that might be restarted someday. According to the Red Book Uranium 2009 [9] there is in Spain a total of 12,300 tons of natural uranium located in different regions such as Salamanca or Andalucia.

\section{Results and analyzes}

Along this section, the main results of the performed analysis are presented. They have been divided into three groups. The first part will deal with the electricity production issues, and some sensitivity analysis will be described. The second part will analyze the capacity of Spain to deploy a nuclear fleet of Gen-IV SFRs in terms of availability of national resources. Finally, some considerations regarding the transmutation capability of the proposed fleet will be addressed.

\subsection{Electricity production}

The first study focuses on the estimation of ESFR-like reactor fleet needed to supply electricity in a hypothetical reference case. As described in Section 4, a progressive evolution from Gen-II to Gen-IV has been considered through the deployment of Gen-III reactors, as shown in Fig. 3.

Fig. 3 shows the target Gen-IV electricity production, which would cover circa $20 \%$ of the electricity share. The selected reference scenario for the Gen-IV deployment assumes: $1.5 \%$ increasing rate for the electricity demand, $38 \%$ thermodynamic efficiency of the nuclear plant and $20 \%$ nuclear electricity share (this will be called case A5).

The analyzed period goes from 2050 (when the technology is assumed to be mature enough to start to be implemented) to 2110 (when the electricity demand is assumed to start to be

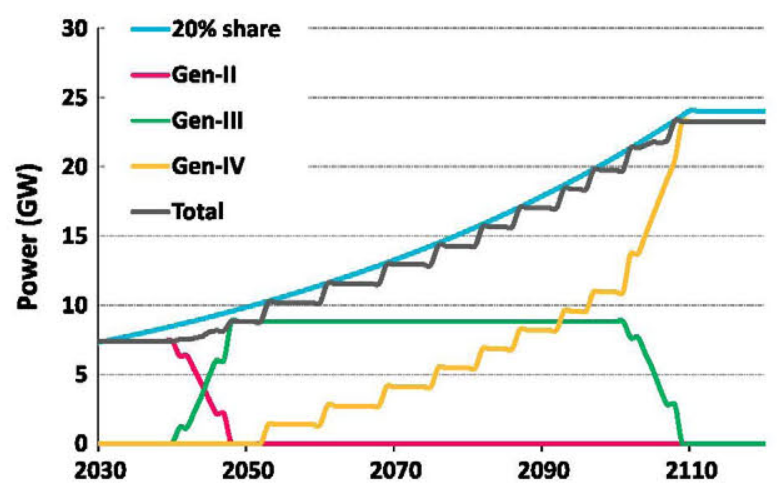

Fig. 3. Power covered by the different technologies of NPP. 
Table 3

Description of considered energy scenarios.

\begin{tabular}{|c|c|c|c|c|c|c|c|}
\hline \multirow[t]{2}{*}{ Name } & \multicolumn{3}{|c|}{ Increasing demand rate } & \multicolumn{2}{|c|}{ Thermal efficiency } & \multicolumn{2}{|c|}{ Nuclear share } \\
\hline & 0.5 & $2.5^{\mathrm{a}}$ & 1.5 & $38 \%$ & $42 \%$ & $20 \%$ & $25 \%$ \\
\hline $\mathrm{A} 1$ & $x$ & & & $x$ & & $x$ & \\
\hline $\mathrm{A} 2$ & $x$ & & & $x$ & & & $x$ \\
\hline $\mathrm{A} 3$ & & $x$ & & $x$ & & $x$ & \\
\hline A4 & & $x$ & & $x$ & & & $x$ \\
\hline A5 & & & $x$ & $x$ & & $x$ & \\
\hline A6 & & & $\mathrm{x}$ & $\mathrm{x}$ & & & $\mathrm{x}$ \\
\hline A7 & $x$ & & & & $\mathrm{x}$ & $\mathrm{x}$ & \\
\hline A8 & $x$ & & & & $x$ & & $x$ \\
\hline $\mathrm{Ag}$ & & $x$ & & & $\mathrm{x}$ & $x$ & \\
\hline A10 & & $\mathrm{x}$ & & & $\mathrm{x}$ & & $\mathrm{x}$ \\
\hline A11 & & & $x$ & & $\mathrm{x}$ & $x$ & \\
\hline $\mathrm{A} 12$ & & & $x$ & & $x$ & & $x$ \\
\hline
\end{tabular}

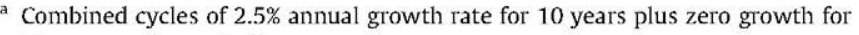
next 2 years and repeatedly.

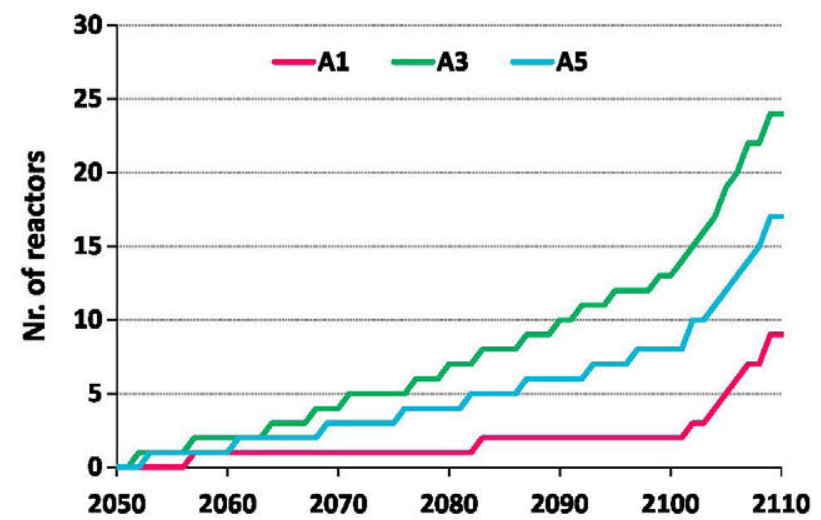

Fig. 4. Estimated reactor fleet requirements for each postulated electricity demand trends.

constant and just the replacement would be considered). An operational life of 60 years has been considered for the SFR reactors. Under those assumptions, a total of 17 reactors would be required to supply the nuclear energy demand until 2110 , after which the first reactors should be replaced by new ones. The availability of resources will be taken into account in the following section. The considered scenarios are described in Table 3 , as a combination of the most representative variables: electricity demand, thermal efficiency and nuclear share of production.

Moreover, some sensitivity analyzes have been performed around the target variables, which are presented in the following sections.

\subsubsection{Electricity demand}

Based on the reference case assumptions (38\% efficiency and $20 \%$ nuclear share), three electricity demand scenarios were stud ied, according to Section 4, with different demand increasing trends:

- Moderate constant development $(+0.5 \%$ annual growth rate) (A1).

- High development by periods (combined cycles of $2.5 \%$ annual growth rate for 10 years plus zero growth for next 2 years and repeatedly) (A3).

- Medium constant development $(+1.5 \%$ annual growth rate) (A5).

The estimated reactor fleet for each of them is presented in Fig. 4.

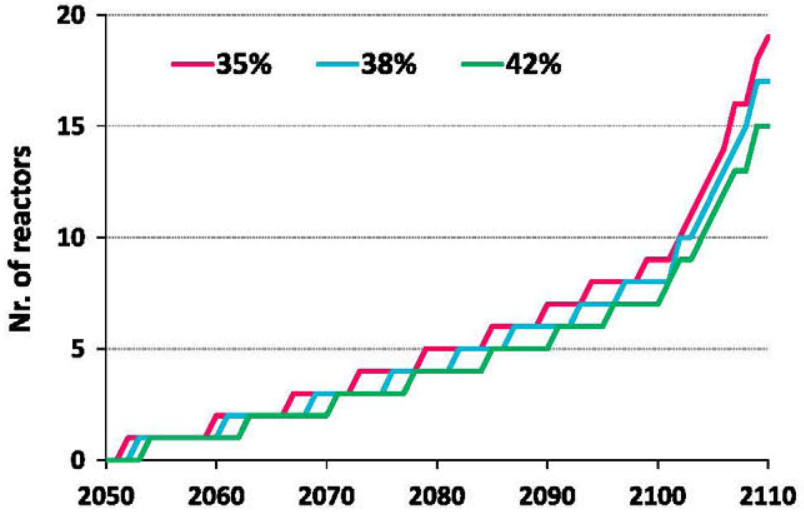

Fig. 5. Estimated reactor fleet requirements for each postulated thermal efficiency.

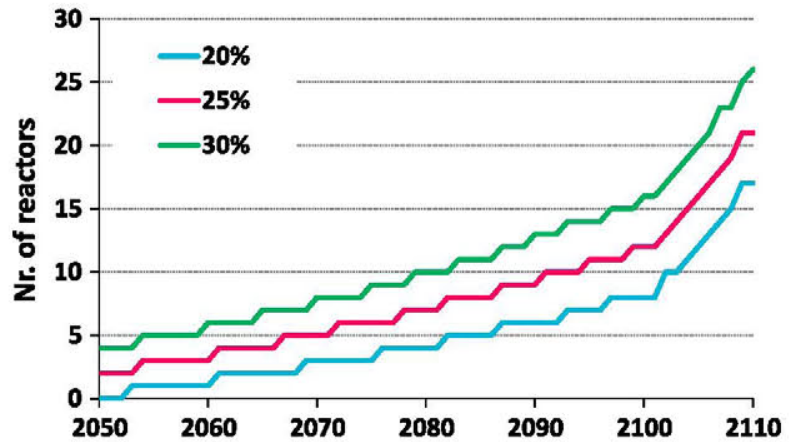

Fig. 6. Estimated reactor fleet requirements for each postulated nuclear electricity share.

A total amount of 9, 24 and 17 reactors, respectively, are estimated to be required for each of the postulated scenarios until 2110. After that moment, the first reactors would need to be replaced by new ones. Concluding, it can be inferred that the proposed electricity demand evolution has a strong impact on the number of reactors required, as it was expected.

\subsubsection{Thermal efficiency}

Based on the reference case (A5), different efficiencies for the conversion of thermal energy into electricity have been postulated: $35 \%, 38 \%$ (A5) and $42 \%$ (A11).

The total estimated fleet for each of the postulated efficiencies presented is 19,17 and 15 , respectively (Fig. 5). It can be drawn that the efficiency impacts but not as much as the electricity demand scenario. Due to the improvement of thermodynamic efficiency, settled as one of the primary objectives of the Gen-IV reactors, an efficiency of $35 \%$, as a conservative option, or even $42 \%$, as an optimistic one, could be achievable.

\subsubsection{Nuclear electricity production share}

Following the assumptions of the reference case, the sensitivity of the share has also been studied. Three different shares have been postulated: $20 \%$ (A5), $25 \%$ (A6) and $30 \%$. For each of them, the required fleet has been calculated as 17,21 and 26 , respectively, as shown in Fig. 6.

Giving the importance of renewal energies in Spain, the energy mix is pursued to be as diverse as possible, and therefore, a nuclear share larger than $25 \%$ is not foreseen. Thus the two first values have been selected as the most representative ones. 
Table 4

Total required fleet for each postulated scenario.

\begin{tabular}{llllllllllll}
\hline A1 & A2 & A3 & A4 & A5 & A6 & A7 & A8 & A9 & A10 & A11 & A12 \\
\hline 9 & 12 & 24 & 30 & 17 & 21 & 8 & 10 & 22 & 27 & 15 & 19 \\
\hline
\end{tabular}

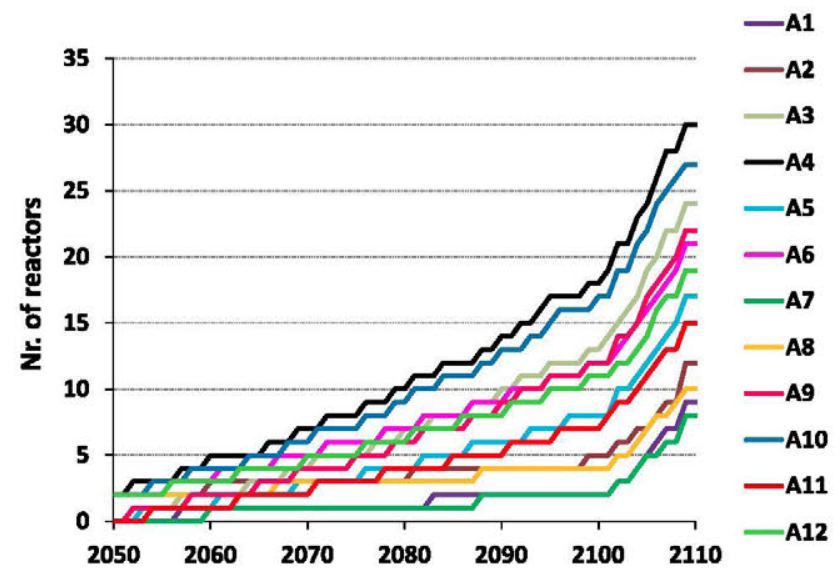

Fig. 7. Estimated reactor fleet required for each postulated scenario.

In order to summarize the previous analysis, the most representative scenarios have been gathered in Table 4, and the estimated reactor fleet for each of them is presented in Fig. 7.

\subsection{Resources}

The second approach consists on the study of the availability of the resources for each considered case. This study aims to analyze the capability of Spain to supply the fleet of SFRs calculated in the previous section with national resources.

The limiting resources in this case, to be considered for the analysis, would be the uranium and plutonium resources. In particular, regarding uranium the study focuses on $U-238$ being the main contributor to the fuel and the responsible of the production (breeding) of fissile matter (Pu-239) through the following reaction:

$\mathrm{U}_{92}^{238}+n \rightarrow \mathrm{U}_{92}^{239} \stackrel{\beta-}{\rightarrow} \mathrm{Np}_{93}^{239} \stackrel{\beta-}{\rightarrow} \mathrm{Pu}_{94}^{239}$

As for plutonium, the $\mathrm{Pu}-239$ isotope is the relevant one for being the fissile material responsible of the criticality at Beginning of Life (BOL).

\subsubsection{Uranium-238}

The aim of this section is to verify the availability of Spanish national resources to supply the postulated fleet according to the reference electricity scenario (A5).U-238 could be obtained from three main channels: mining, reprocessing and from waste of fuel enrichment process (depleted uranium). Thus, different combinations of these three sources were postulated:

- B1. U-238 obtained only from mining.

- B2. U-238 obtained from both mining and reprocessing.
Table 6

Pu-239 (ton) available and start-up reactors.

\begin{tabular}{llll}
\hline & $40 \mathrm{y}$ & $60 \mathrm{y}$ & $60 \mathrm{y}+$ GIII $(2050)$ \\
\hline Pu-239 available (ton) & 49.29 & 73.94 & 82.03 \\
Whole life reactors & 0.81 & 1.21 & 1.34 \\
Start up reactors & 4 & 6 & 7 \\
\hline
\end{tabular}

Table 7

Description of postulated breeding scenarios.

\begin{tabular}{|c|c|c|c|c|c|c|}
\hline \multirow[t]{2}{*}{ Name } & \multicolumn{2}{|l|}{ Core } & \multicolumn{2}{|c|}{ Operational life } & \multicolumn{2}{|c|}{ Electricity scenario } \\
\hline & HET2 & CONF2 & $40 y$ & $60 y+$ Gen-III & A3 & A5 \\
\hline $\mathrm{C} 1$ & $\mathrm{x}$ & & $\mathrm{x}$ & & & $\mathrm{x}$ \\
\hline $\mathrm{C} 2$ & & $\mathrm{x}$ & $\mathrm{x}$ & & & $\mathrm{x}$ \\
\hline $\mathrm{C} 3$ & & $\mathrm{x}$ & & $\mathrm{x}$ & & $\mathrm{x}$ \\
\hline C4 & & $x$ & & $x$ & $x$ & \\
\hline
\end{tabular}

- B3. U-238 obtained from both mining and enrichment wastes.

- B4. U-238 obtained from mining, reprocessing and enrichment wastes.

In addition, the extension of the Spanish nuclear power plants operational lives from 40 to 60 years has been considered, giving rise to two further scenarios:

- B5. U-238 obtained from both mining and reprocessing (after 60 years).

- B6. U-238 obtained from mining, reprocessing (after 60 years) and enrichment wastes.

No U-238 reprocessing for Gen-III fleet has been considered. However, it remains as an additional source in case of needed.

First, the amount of $U-238$ required for a whole life of a nuclear ESFR-type reactor was estimated as circa 659 ton. No U-238 recycling from the SFR operating fleet was envisaged. Second, the total availability of $\mathrm{U}-238$ following the different paths (B1-B6) was calculated (Table 5), and consequently, the maximum number of reactors able to be fed was estimated for each scenario.

Therefore, comparing Tables 4 and 5 , it is concluded that the Uranium-238 is not a limitation for most of the postulated combinations. In particular, for the reference scenario (A5), where 17 reactors were required, no limitation is expected until 2110. In fact, there only exist a limitation when the U-238 can just be achievable from the mining (B1) in combination to the most demanding scenarios ( $\mathrm{A} 3, \mathrm{~A} 4, \mathrm{~A} 6, \mathrm{~A} 9, \mathrm{~A} 10$, and $\mathrm{A} 12$ ), or in case of considering just mining and reprocessing without lifetime extension (B3) in combination with the electricity scenario A4.

\subsubsection{Plutonium-239}

This section deals with the study of the availability of the fissile isotope employed in Fast Reactors, Pu-239. This isotope cannot be obtained from the nature, as uranium is, but only from spent fuel reprocessing. Thus, along these lines the amount of Pu-239 extractable from the spent fuel disposal coming from the Spanish nuclear power plants will be estimated.

U-238 (ton) available and max. fleet according to each scenario (B1-B6)

\begin{tabular}{|c|c|c|c|c|c|c|}
\hline & B1 & $\mathrm{B} 2$ & B3 & B4 & B5 & B6 \\
\hline U-238 available (ton) & 12213.9 & 64380.4 & 18484.6 & 70651.1 & 21619.9 & 80057.2 \\
\hline Max. fleet & 18 & 97 & 28 & 107 & 32 & 121 \\
\hline
\end{tabular}




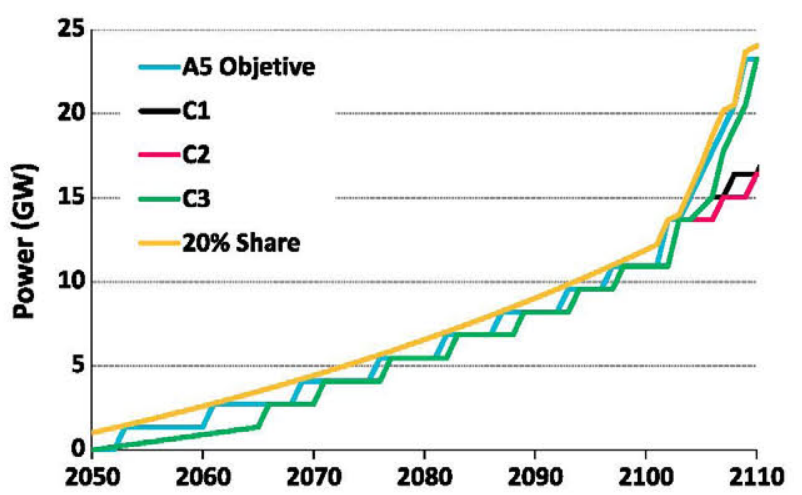

Fig. 8. Estimated power produced for the A5 scenario.

Three possibilities have been considered for the estimation of the $\mathrm{Pu}-239$ requirements:

- No lifetime extension of current fleet (Gen-II).

- Lifetime extension to 60 years of current fleet (Gen-II).

- Lifetime extension to 60 years of Gen-II and substitution by Gen-III (until 2050).

Then, the amount of Pu-239 required for a whole life of a ESFRlike reactor is estimated as around 61 tons. Comparing it with the total amount of Pu-239 available, it can be verified that there would be enough to feed maximum a single reactor whole life, in case of lifetime extension, as shown in Table 6.

However, there is enough plutonium to feed a number of startup cores, which can start producing plutonium, thanks to the breeding properties of this kind of reactors. Therefore, the number of start-up cores able to start operating with autonomy of 2050 EFPD was estimated. A constant reprocessing strategy is considered in order to obtain the required resources from the operating reactors. In this regard, the plutonium availability taking into account the production and consumption is updated every year. The produced plutonium is assumed to come from both Gen-IV and Gen-III operating reactors, depending on the case, while the plutonium is assumed to be consumed only by the Gen-IV operating reactors. For the reprocessing cycle an efficiency of $99.9 \%$ was considered, and the assumption of 5 years of spent fuel cooling followed by 1 year of reprocessing was employed.

The final objective of the present analysis is to verify if there would be enough plutonium to generate the power demanded by the reference scenario (A5), by means of reprocessing the plutonium obtained by the operating reactors. Following this purpose, a burn-up calculation was performed using SERPENT for the CONF2 and CONF2-HET models. The reloading was envisaged each 410 days, but for the first cycle, no reprocessing is expected until the equilibrium cycle (2050 EFPD) is achieved. Both designs include a fertile blanket aimed to produce plutonium. In addition, the CONF2-HET2 configuration was employed for its better breeding properties, thanks to the production of $\mathrm{Pu}-239$ in the additional external ring.

A total of four scenarios have been postulated including a combination of the following specifications as described in Table 7:

- Core: HET2 core or CONF2.

- Operational life: 40 years (Gen-II) or 60 years + GEN-III, where the available plutonium is updated after each Gen-III operational year.

- Electricity scenario: Reference (A5) or a more demanding electricity scenario (A3).

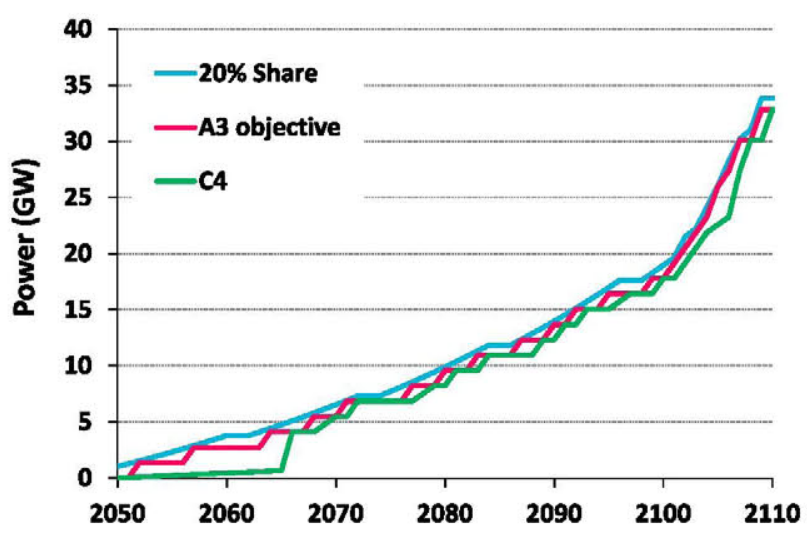

Fig. 9. Estimated power produced for the $A 3$ scenario.

The prior objective is to verify the Pu-239 availability in order to achieve the electricity scenario demanded by Section 5.1. In particular, to verify if the reference scenario (A5) is achievable with the hypotheses presented.

Following this motivation, Figs. 8 and 9 show the estimated power production with the available Pu-239 according to the postulated scenarios for the reference electricity scenario (A5) and for the more demanding one (A3), respectively.

It is inferred from Fig. 8 that there would be enough Pu-239 to produce circa $20 \%$ of the electricity demand according to the reference scenario $\mathrm{A5}$, when the $\mathrm{Pu}-239$ is reprocessed from the spent fuel of both Gen-II and Gen-III (C3). The HET2 core has proved to breed more plutonium, as expected. As the Gen-III NPPs start to shut down, the required fleet of Gen-IV increases to cover their share. As a consequence, for the cases $\mathrm{C} 1$ and $\mathrm{C} 2$, from 2102 to 2120 the nuclear share is lower than $20 \%$.

In case of the more demanding electricity scenario (A3), assuming reprocessing from both Gen-II (with lifetime extended to 60 years) and Gen-III, there would be enough plutonium to generate $20 \%$ of the electricity share.

As a conclusion, there would be enough Pu-239 to contribute circa the $20 \%$ to the electricity production in the reference scenario as long as reprocessing both Gen-II and Gen-III wastes is considered.

\subsection{Waste reduction by transmutation}

For MA transmutation assessment the HOM4 model was employed where all fuel pellets in the ESFR reactor core contain $4 \%$ of MA homogeneously distributed (Section 2.1). The transmutation performances of the three designs described in Section 2.1 were previously compared in [30]. Moreover, for the purpose of the present analysis, a different approach was considered. Two different assumptions were compared: in one case the HOM4 fuel was burned during 2050EFPD, while in the second one the same fuel from the HOM4 design is left to decay in the temporal storage centre instead.

Depletion calculations performed with SERPENT code estimate the mass of MA that will be eliminated during the 2050 days of permanence in the reactor. Fig. 10 shows the comparison between the MA isotopes at Beginning of Life (BOL) and End of Life (EOL).

Complementary, the decay heat of the two postulated cases were compared, when the same fuel is burned in the reactor and when it is left to decay instead. Fig. 11 shows the evolution of decay heat of those materials after around 60 years after disposal. The net reduction in terms of decay heat might be drawn from Fig. 11 as well. The decay heat of the most characteristic elements is also represented, comparing the impact of being burned in the reactor. 


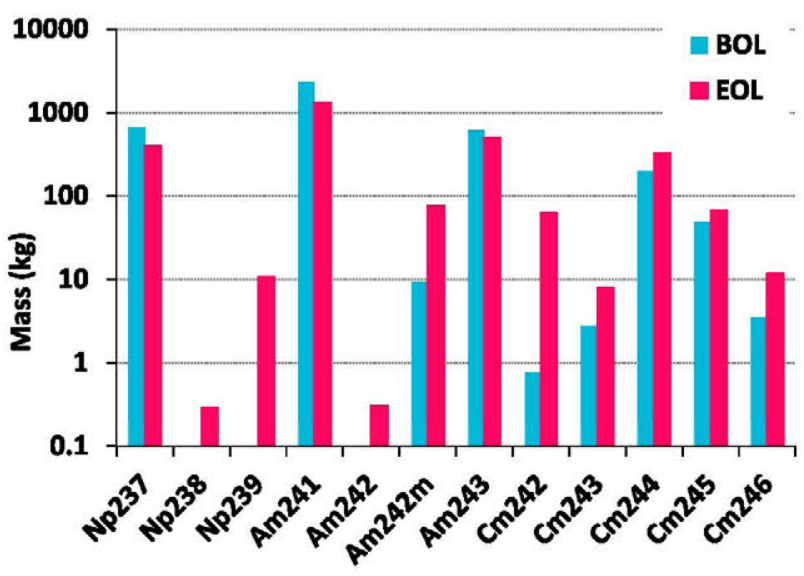

Fig. 10. Main MA isotopes' masses at BOL and EOL.

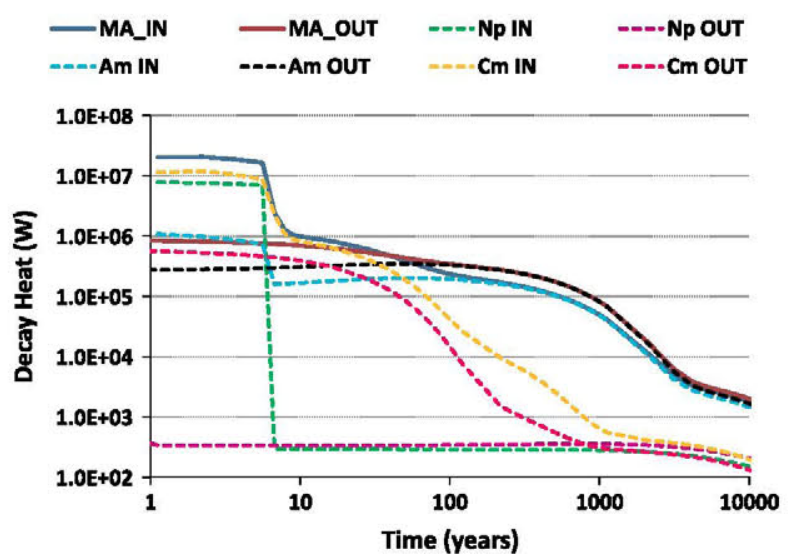

Fig. 11. Comparison of the activity of the main MA being burned in the reactor or not.

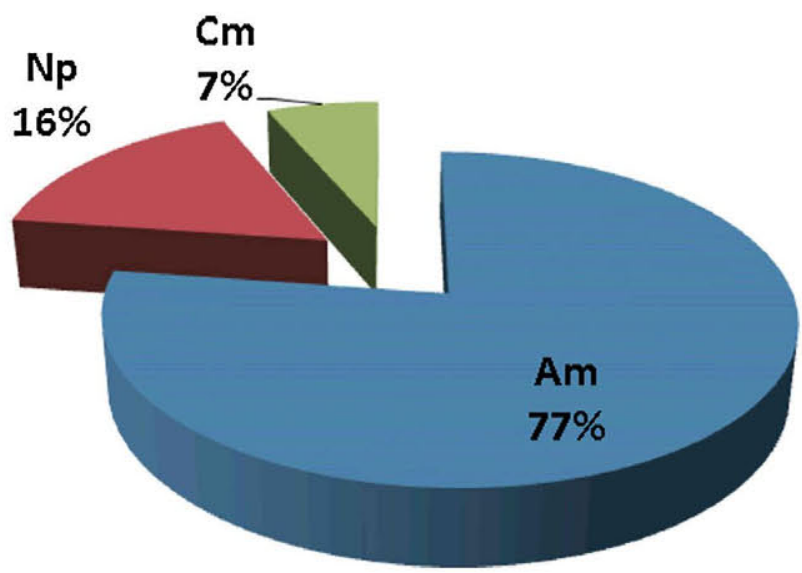

Fig. 12. MA content in the wasted fuel.

Fig. 11 shows that the contribution of Am-241 and Am-243 to the decay heat is significantly reduced in the reactor, as well as the one from $\mathrm{Np}-237$. However, the contribution of $\mathrm{Cm}$ isotopes increases.

The total decay heat from the MA in case of being burned in the reactor is lower than the corresponding to the temporal storage after 60 years of discharge, even though it is higher during the first period. The main minor actinides elements are also represented in case of going through the reactor (IN) or not (OUT). The main responsible of reducing the total MA decay heat is the Am, which is eliminated significantly in the reactor. On the other hand, although the $\mathrm{Cm}$ isotopes mass increases in the reactor, its activity is quickly reduced.

Furthermore, the total nuclear waste accumulated from the Spanish nuclear power plants is calculated to be 6675 tons by 2030 , as mentioned in Section 4. It is assumed that the $0.1 \%$ are minor actinides, which means a $6675 \mathrm{~kg}$ of minor actinides (Am, $\mathrm{Np}$, and $\mathrm{Cm}$ ) following the usual proportion in spent fuel, Fig. 12.

Using the previous data, it has been estimated that the $39 \%$ and $43 \%$ of the initial Am and Np, respectively, will be consumed in each cycle. However, a small quantity of $\mathrm{Cm}$ will be created. Only one SFR is needed to operate with MA in the first cycle, later on some more cycles would be needed to transmute the generated MA.

\section{Conclusions}

An analysis of a Spanish energy scenario using one type of GenIV reactor has been performed in terms of electricity production, availability of resources and wastes reduction.

Three sensitivity studies to the required fleet of ESFR-like reactors have been done: different electricity demand scenarios, thermal to electrical conversion efficiencies and shares covered by nuclear electricity. It was confirmed that the most relevant factor is the electricity demand.

To study deeply some parameters, a reference scenario has been fixed with the hypothesis of $1.5 \%$ of annual growth of the demand, $38 \%$ of thermal efficiency and $20 \%$ of nuclear power. For this reference scenario, the availability of the most representative resources, i.e. uranium (U-238) and plutonium (Pu-239), has been assessed.

For uranium, it can be concluded that there is no limitation for the exploitation of the proposed fleet for the reference case scenario assuming different alternatives in the ways the uranium might be obtained. When the study is extended to further energy scenarios, a limitation appears in the most restrictive scenarios. In case of using only resources from national uranium mines, there would not be enough uranium to feed the required fleet for the most demanding energy scenarios. Nevertheless, if reprocessing is possible and the operational life is extended to 60 years, there would not be any limitation to feed the required fleet by any of the postulated scenarios.

Regarding plutonium, it can be concluded that as the only way to obtain $\mathrm{Pu}$ is from the reprocessing of the spent fuel, there is not enough plutonium to feed the complete fleet. However, thanks to the breeding properties of the ESFR-like reactors, a strategy involving the continuous reprocessing of plutonium has been proposed in order to obtain enough plutonium to feed reactors' cycles until the desired production level is achieved. The real power production capacity has been assessed for the reference scenario according to different parameters. It is concluded that for the CONF2 core it would be possible to achieve the reference case scenario energy demand, as far as the on-the-fly reprocessing from the 60 -yearsof-operational-lifetime Gen-II and future Gen-III is considered.

In addition to those studies, the capability of reducing the quantity and decay heat of the most radioactive isotopes presented in the spent fuel, i.e. the minor actinides, is assessed. The study concludes that the whole decay heat of the MA is reduced after 60 years when fuel with MA is burned in the reactor, compared with the case when it is left to decay in a temporal storage centre. The main responsible of this result is the reduction of Am isotopes when the fuel is burned.

\section{Acknowledgements}

Authors want to acknowledge the different institutions referenced for providing the required information for this analysis. In 
special, the CP-ESFR project from the European Community's Seventh Framework Program [FP7/2007-2013], for providing the reactor specifications used as a reference for this analysis.

\section{References}

[1] Our common future: report of the World Commission on Environment and Development. Oxford: Oxford University Press; 1987. <http://www.undocuments.net/wced-ocf.htm_1>.

[2] Fiore K. Nuclear energy and sustainability: understanding ITER. Energy Policy $2006 ; 34: 3334$

[3] Clift R. Climate change and energy policy: the importance of sustainability arguments. Energy 2007;32:262-8.

[4] Hernandez F et al. Energy sustainability and global warming in Spain. Energy Policy 2004:32:383-94

[5] Tainter JA. Energy, complexity, and sustainability: a historical perspective. Environ Innovation Soc Transitions 2011. http://dx.doi.org/10.1016/ j.eist.2010.12.001.

[6] Onat $\mathrm{N}$ et al. The sustainability indicators of power production systems. Renew Sust Energy Rev 2010;14:3108-15.

[7] Martínez-Val JM, Piera M. Nuclear fission sustainability with hybrid nuclear cycles. Energy Convers Manage 2007;48:1480-90.

[8] Goethem V. Nuclear fission, today and tomorrow: from renaissance to technological breakthrough (Generation IV) - Part I (and II), ATW 55, 7 Juli (and 8/9, August/September); 2010.

[9] NEA. Uranium 2009: resources, production and demand. Paris: OECD Publications [07/28/2010].

[10] Grover RB. Policy initiatives by the government of India to accelerate the growth of installed nuclear power capacity in the coming years. Energy Procedia 2011;7:74-8.

[11] Jacobson MZ et al. Providing all global energy with wind, water, and solar power. Part 1: Technologies, energy resources, quantities and areas of infrastructure, and materials. Energy Policy 2011;39:1154-69.

[12] Delucchi MA et al. Providing all global energy with wind, water, and solar power. Part 11: Reliability, system and transmission costs, and policies. Energy Policy 2011:39:1170-90.

[13] Fthenakis V. Sustainability of photovoltaics: the case for thin-film solar cells. Renew Sust Energy Rev 2009;13:2746-50.
[14] Lenzen M. Life cycle energy and greenhouse gas emissions of nuclear energy: a review. Energy Convers Manage 2008;49:2178-99.

[15] Uemura $S$ et al. Environmental and economical assessment of various fusion reactors by the calculation of $\mathrm{CO}_{2}$ emission amount. Proc ITC18 2008:1-40.

[16] Kessler G. Requirements for nuclear energy in the 21st century: nuclear energy as a sustainable energy source. Prog Nucl Energy 2002;40(3-4):309-25.

[17] Piera M. Sustainability issues in the development of Nuclear Fission energy. Energy Convers Manage 2010;51:938-46.

[18] Andrews A. Nuclear Fuel Reprocessing: U.S. Policy Development. Congressional Research Service Report to the Congress. Order Code RS22542; Updated March 27, 2008.

[19] ENRESA. VI Plan General de Residuos Radiactivos; September 2009. NIPO 70106-031-6. M-38978-2006. <http://www.enresa.es/files/multimedios/ dossier_pgrr_200903.pdf>.

[20] Chetal SC et al. Current status of fast reactors and future plans in India. Energy Procedia 2011;7:64-73.

[21] Zhou Y. China's spent nuclear fuel management: current practices and future strategies. Energy Policy 2011;39:4360-9.

[22] Asmolov VG et al. Innovative development of nuclear power in Russia. At Energy 2007;103(3).

[23] Rineiski A et al. Synthesis of options to optimize feedback coefficients, SP2.1.3.D1. 2011. CP-ESFR Project.

[24] Fiorini GL, Vasile A. European commission - 7th framework programme. The collaborative project on European sodium fast reactor (CP ESFR). Nucl Eng Des 2011;241:3461-9.

[25] Leppänen J. PSG2/serpent - a continuous-energy Monte Carlo reactor physics burnup calculation code. User's manual; 2011.

[26] Meulekamp RK, van der Marck SC. Calculating the effective delayed neutron fraction with Monte Carlo. Nucl Sci Eng 2006;152(2006):142-8.

[27] Pusa M, Leppänen J. Computing the matrix exponential in burnup calculations. Nucl Sci Eng 2010;164(2):140-50.

[28] Pusa M. Rational approximations to the matrix exponential in burnup calculations. Nucl Sci Eng 2011;169(2):155-67.

[29] Energy. Foro de la Industria Nuclear Española. M-24589-2012; 2012.

[30] Ochoa R et al. A comparative study of Monte Carlo-coupled depletion codes applied to a sodium fast reactor design loaded with minor actinides. Ann Nucl Energy 2013;57:32-40. 